\title{
trabalnenecessário
}

issn: $1808-799 \mathrm{X}$

ano 4 - número 4 - 2006

\section{A REFORMA DO ENSINO MÉDIO: competências para o "novo" mundo do trabalho?}

Maria José Pires Barros Cardozo*

O presente artigo expressa algumas inferências preliminares dos estudos que estamos desenvolvendo no Doutorado em Educação Brasileira da Universidade Federal do Ceará. Procuramos desenvolver algumas reflexões sobre a reforma do ensino médio no atual contexto do capitalismo, considerando as mudanças provocadas pela chamada produção flexível na configuração do mercado de trabalho e nas demandas formuladas à educação escolar, sobretudo ao "novo" papel que é conferido ao ensino médio na formação de competências básicas que possibilitem aos alunos mobilizar saberes em contextos apropriados, de modo que sejam capazes de transferir capacidade de resolução de problemas para a vida social e, especialmente para o mundo produtivo.

Para a realização deste estudo estamos definindo categorias que nos darão elementos que nos possibilitem analisar as relações entre a reformado ensino médio e a chamada produção flexível, frente às demandas do capitalismo contemporâneo. Estamos também coletando dados que nos permitirão analisar a ênfase que é dada ao ensino médio no que se refere à formação das competências básicas que estão sendo exigidas pelo mundo do trabalho.

\section{1- A emergência do conceito de competência no discurso educacional}

Inicialmente, é importante ressaltarmos que o modelo da competência surgiu do discurso empresarial francês e, segundo HIRATA (1996), depois de ser definido como lógica póstaylorista, foi assimilado pelos empresários europeus e grupos envolvidos com as reestruturações administrativas, que passaram a valer-se da noção de competência para defender e implementar mudanças na organização do trabalho. Tal postura possibilitaria associar as qualidades requeridas do indivíduo e as formas de cooperação intersubjetivas características novos paradigmas produtivos.

Segundo DUBAR (1998), sendo a qualificação um dos pontos capitais do compromisso fordista, cedeu-se à tentação de substituí-la pela competência como base de um novo 
modelo de gestão acompanhando a transformação da organização do trabalho (ruptura patenteada com o taylorismo) e a mudança na relação de forças entre patrões e sindicatos de assalariados (declínio acentuado da sindicalização e das negociações coletivas). Essa mudança foi igualmente possibilitada pelas evoluções do sistema educativo que colocava a aquisição das competências no cerne de seus objetivos ao reformar os modos de construção de diplomas profissionais e a concepção de avaliação (1998, p. 97).

Algumas vezes o conceito de competência é usado como sinônimo de qualificação, porém, ele apresenta conotações diferentes, á medida que enfatiza a mobilização de saberes técnicos para serem utilizados em situações imprevistas de trabalho e não a posse de tais saberes.

O conceito de competência coaduna-se com a idéia de polivalência, uma vez que esta última significa uma racionalização formalista com fins instrumentais que enfatiza os conhecimentos empíricos disponíveis, porém a ciência permanece algo exterior e estranho ao trabalhador (MACHADO, 1995).

Para DUBAR, o modelo da competência não é novo, nem mais racional do que os outros. "Ele corresponde a uma concepção das relações sociais de trabalho que valoriza a empresa e o contrato individual de trabalho" (1998, p.99). Portanto, tal enfoque permite concentrar a atenção mais sobre a pessoa do que sobre o posto de trabalho, à medida que não exigiria um trabalhador qualificado para uma função específica, mas portador de conhecimentos que lhe permita se movimentar por todo o processo produtivo, apontando e solucionado problemas que venha ocorrer.

Nessa perspectiva, DUBAR destaca que a

noção de competência serve para significar o caráter fortemente personalizado dos critérios de reconhecimento que devem permitir recompensar cada um em função da intensidade de seu empenho subjetivo e de suas capacidades "cognitivas" em compreender, antecipar e resolver os problemas de sua função que são também os de sua empresa (1998, p.98).

Para TANGUY (1997) o uso da noção de competência na educação e no trabalho está associado a uma série de movimentos e crenças nesses dois campos, dentre os quais ela destaca: a necessidade de superar a ênfase na instrução e privilegiar a educação; reconhecimento da importância do poder de conhecimento por todos os meios sociais e de que a transmissão do conhecimento não é tarefa exclusiva da escola; a institucionalização e sistematização de princípios sobre a formação contínua fora do âmbito escolar; exigência de superar a qualificação profissional precária e baseada em aprendizagens mecânicas; necessidade de rever o ensino disciplinar e o saber academicista ou descontextualizado.

As concepções e crenças elementos e a necessidade de adaptar a educação às 
demandas do mundo do trabalho, acabaram por propiciar uma apropriação generalizada da noção de competência em vários países e a sua disseminação nas escolas.

Portanto, a emergência do modelo de competência atende a três propósitos: reordenar conceitualmente a compreensão da relação trabalho-educação, desviando o foco dos empregos, das ocupações e das tarefas para o trabalhador em suas dimensões subjetivas com o trabalho; institucionalizar novas formas de educar/formar os trabalhadores e de gerir o trabalho internamente às organizações e no mercado de trabalho em geral, sob novos códigos profissionais que configuram as relações contratuais, de carreira e de salário; formular padrões de identificação da capacidade real de trabalho para determinada ocupação, de tal modo que possa haver mobilidade entre as diversas estruturas de emprego em nível internacional e nacional (RAMOS, 2001).

No âmbito desse cenário o discurso empresarial, governamental e sindical coloca à educação a função de desenvolver competências cognitivas, cuja importância vem sendo cada vez mais enfatizada pelo mundo do trabalho: criatividade, capacidade de análise e de solucionar problemas imprevisíveis, prospecção etc. São valorizados os conteúdos curriculares da educação básica que, devem contribuir para a aprendizagem de competências básicas, a fim que os indivíduos estejam aptos para assimilarem mudanças e sejam mais autônomas.

Nesse sentido, o papel das escolas deveria ser direcionado para preparar os indivíduos para a empregabilidade. Entretanto, formar para a empregabilidade, significa também formar para o trabalho precário e para desemprego, numa lógica que transforma a dupla: trabalho/falta de trabalho numa união inseparável, uma vez que a acumulação capitalista produz constantemente, em proporção à sua intensidade e à sua expansão, uma população excedente, supérflua e desprovida não só dos meios materiais, mas dos meios de procurar trabalho.

No plano educacional o modelo pedagógico centrado na competência expressou-se inicialmente no ensino técnico profissionalizante por meio da avaliação -dado o comprometimento mais imediato dessa modalidade de ensino com o processo produtivo e, posteriormente passou a ser adotado implícita e explicitamente na educação em geral. Esse direcionamento para as competências está destacado no Relatório da UNESCO que foi elaborado pela Comissão Internacional sobre Educação para o Século XXI. Esse documento expressa as competências como um dos principais elementos que deve direcionar a prática pedagógica nas escolas de ensino médio e profissionalizante. No Brasil a partir da aprovação da LBD 9394/96 a noção de competência passa a compor as diretrizes curriculares e a re-orientar o trabalho pedagógico em favor da transmissão de conteúdos voltados para a construção de competências. As matrizes curriculares de referencia para o Sistema de Avaliação da Educação Básica (SAEB), apresentam um rol de competências, o que indica que a partir do ensino fundamental a o conceito de competência deve ser assumido como princípio organizador do currículo.

Assim partir do relatório da UNESCO e dos princípios da LDB 9.394/96 e das matrizes 
curriculares de referencia para o SAEB, o MEC através dos Parâmetros Curriculares para o Ensino Médio, definiu novas diretrizes esse nível de ensino, visando superar a visão academicista e propedêutica do currículo anterior que, segundo seus técnicos, é estritamente voltado para o acesso ao ensino superior. Portanto, tais técnicos defendiam que era necessário direcioná-lo para uma concepção de educação geral que procurasse desenvolver as competências e habilidades dos alunos de modo a atender às exigências da sociedade contemporânea e da produção pós-fordista.

Em artigo denominado "Competências, conhecimentos e valores na concepção curricular do novo ensino médio" o MEC propõe que a nova organização curricular ao invés de uma lista de disciplinas e de conteúdos obrigatórios deve ser composta por um conjunto de competências e habilidades a serem construídas pelos educandos ao longo de três anos de ensino médio, sendo que muitas vezes essas competências e habilidades pressupõem a consolidação e o aprofundamento de aprendizagens anteriores (BRASIL/ MEC, 2004). Esse documento enfatiza ainda que é necessário superar a superlotação do currículo tradicional, demasiadamente inchado de conteúdos muitas vezes inexpressivos do ponto de vista da vida concreta dos educandos fora da escola. Daí a ênfase na aquisição das competências e habilidades básicas para o cidadão viver plenamente nas dimensões pessoal, civil e profissional (BRASIL/MEC, 2004).

Nessa perspectiva as competências e habilidades são apresentadas como "modalidades estruturais da inteligência. São os esquemas mentais de que nos fala Piaget, constituindo antes um conjunto de potencialidades e possibilidades do que resultados ou desempenhos" (BRASIL/MEC, 2004, p. 3).

No documento denominado Eixos cognitivos do enem (2002) o MEC destaca que o Exame Nacional do Ensino Médio- ENEM foi estruturado a partir de uma matriz de cinco competências que são essenciais ao desenvolvimento e preparo dos alunos para enfrentar as exigências do mundo contemporâneo: dominar linguagens; compreender fenômenos; enfrentar situações -problemas; construir argumentações e elaborar propostas, construir argumentações e elaborar propostas.

Essas competências são descritas nas operações formais de Piaget, ttais como: capacidade de levantar todas as possibilidades para resolver um problema, formulação de hipóteses, combinação de todas as possibilidades e separar varáveis para testar a influência de vários fatores, uso do raciocínio hipotético dedutivo, interpretação, análise e comparação, argumentação e generalização de diferentes conteúdos.

É importante ressaltarmos que segundo Piaget o desenvolvimento cognitivo ocorre por meio da interação do sujeito com o mundo exterior, em um processo de adaptação constituído por dois pólos: a assimilação e a acomodação. A assimilação ocorre quando a criança aplica sobre os objetos os esquemas de que já dispõe ou que já foram adquiridos. A acomodação ocorre quando o ambiente força o aparecimento de uma nova resposta. Assim, o sujeito precisa reorganizar os elementos de que dispõe, fazendo variar os esquemas, ou seja, acomodá-los em função das exigências que o meio lhe faz (PIAGET, 
1976).

Ainda segundo esse documento o modelo de avaliação proposto busca medir e qualificar as estruturas mentais que permeiam as interações do sujeito com a realidade física e social hoje cheia de contínuas transformações. Além disso, foca particularmente as competências e habilidades básicas que, teoricamente, são desenvolvidas, transformadas e aperfeiçoadas também por meio da mediação da escola (BRASIL/MEC/INEP, 2002). De acordo com os idealizadores da reforma do ensino médio a noção de competência adotada está ancorada em princípios que se aproximam da perspectiva construtivista. Entretanto, observamos que de fato ela se fundamenta na perspectiva funcionalista, ao apresentar a noção de competência como atos observáveis ou comportamentos específicos de acordo com os perfis de competências as descrições de atividades requeridas pela natureza do trabalho e nas tradições ligadas às taxionomias que defendem a concepção de aprendizagem por objetivos, ou seja, a construção de instrumentos de aferição de capacidades e habilidades cognitivas, afetivas e psicomotoras. No mesmo sentido encaminham-se os Referenciais Curriculares do Ensino Médio do Estado do Maranhão, ao enfatizar que a

formação humana, para a vida social e produtiva, não mais repousa sobre a aquisição de modos de pensar e fazer bem definidos de acordo com a função a ser ocupada, mas passa a ser concebida como um resultado da articulação de diferentes elementos, pela mediação das relações que ocorrem no trabalho e na vida coletiva (MARANHÂO/GDH, 2003, p. 18).

Desse modo, podemos destacar que um dos aspectos fundamentais da chamada pedagogia das competências é tentar tornar o individuo cada vez mais dependente da produção do valor de troca, expressando um caráter integrador à lógica do capital, à medida que defende aprendizagens necessárias às mudanças do mundo do trabalho de forma a assegurar a hegemonia do capital baseada no aumento da produção e na crescente diminuição do número de trabalhadores necessários à produção de mercadorias.

Ao eleger a competência como elemento central dos processos formativos, dando-lhe um caráter disciplinador à medida que o saber-ser para além do saber-fazer procura estabelecer um vinculo entre os padrões, atitudes e valores e às necessidades postas pelas empresas, os idealizadores da reforma ressaltam os atributos individuais dos trabalhadores numa perspectiva subjetivista e esquecem que as competências devem ser compreendidas como síntese de múltiplas dimensões, não podendo, portanto serem restritas ao espaço e tempo escolar ou da formação profissional.

Ademais, conforme esclarece Gramsci, mediante a atividade teórico-prática o homem começa a criar os primeiros elementos de uma intuição do mundo liberta de toda magia e bruxaria e fornece um ponto de partida para o posterior desenvolvimento de uma visão de mundo histórico-dialética, ou seja, para a compreensão do movimento e do devir, para a 
valorização da soma de "esforços e de sacrifícios que o presente custou ao passado e que o futuro custa ao presente, para a concepção da atualidade como síntese do passado, de todas as gerações passadas, que se projeta no futuro" (GRAMSCI, 1968, p. 130).

\section{2- Competências para qual trabalho?}

Outro aspecto da reforma do ensino médio é separação entre a educação geral e o ensino técnico e, a ênfase dada à educação geral e na formação de competências básicas para o trabalho, ou seja, uma identificação deste nível de ensino como formação básica articulada com a educação tecnológica.

Essa concepção aparece no texto das Diretrizes Curriculares Nacionais para Ensino Médio -DCNEM da seguinte forma:

O novo paradigma emana da compreensão de que cada vez mais, as competências desejáveis ao pleno desenvolvimento humano aproximam-se das necessárias à inserção no processo produtivo [.....]. Ou seja, admitindo-se tal correspondência entre as competências exigidas para o exercício da cidadania e para as atividades produtivas, recoloca-se o papel da educação como elemento de desenvolvimento social (BRASIL, MEC/SEMTC, 1999, p. 19)

A noção de competência e a vinculação da educação ao mundo do trabalho tornaram-se um guarda-chuva que serve a tudo e a todos. Assim, a ênfase na preparação para o trabalho expressada pelas DCNEM, destaca que tal preparação abarcaria, portanto os "conteúdos e competências de caráter geral para a inserção no mundo do trabalho e aqueles que são relevantes ou indispensáveis para cursar uma habilitação profissional e exercer uma profissão técnica" (BRASIL/MEC, 1999, p. 86).

A formação de competências básicas para o trabalho expressada nas DCNEM é defendida como necessária para a compreensão da tecnologia e da produção na sociedade pós-industrial. Nesse sentido, o texto das DCNEM estabelece que para tanto,

às escolas de ensino cabe contemplar, em sua proposta pedagógica e de acordo com as características regionais e de sua clientela, aqueles conhecimentos, competências e habilidades de formação geral e de preparação básica para o trabalho que sendo essenciais para uma habilitação específica, poderão ter os conteúdos que lhe deram suporte igualmente aproveitados no respectivo curso dessa habilitação profissional(BRASIL/MEC, 1999, p.17).

Os Referenciais Curriculares do Ensino Médio do Estado do Maranhão também reforçam essa idéia ao enfatizar que "a educação deve atender as profundas e rápidas transformações de ordem científico-tecnológica que atingem a sociedade contemporânea" (MARANHÂO/GDH, 2003, p. 18). Dessa forma, os princípios pedagógicos estruturantes do currículo são assentados sobre os eixos da interdisciplinaridade, contextualização e flexibilidade que atendem a legislação vigente quanto aos seguintes aspectos: vincular a educação ao mundo do trabalho e à prática social; preparar-se para o trabalho e o exercício da cidadania; ter flexibilidade para adaptar-se a novas condições de 
ocupação e compreender os fundamentos científicos e tecnológicos dos processos produtivos (MARANHÂO/GDH, 2003).

Essa preparação básica para o trabalho segundo as diretrizes oficiais pode ser efetivada tanto nos conteúdos da base nacional comum como na parte diversificada do currículo, sendo que os conteúdos tratados no contexto do trabalho podem ter caráter profissionalizante, ou seja, podem ser aproveitados em cursos de habilitação profissional mesmo que cursados dentro da carga horária mínima prevista para o ensino médio. Ao estabelecer que a parte diversificada até o limite de $25 \%$ da carga horária total do ensino médio (2.400 horas) pode ser aproveitada para eventual habilitação profissional, a reforma, segundo análise de MAIA FILHO (2004), é uma contradição em termos, por dois aspectos: primeiro porque implica nos fazer acreditar que saída é puramente pedagógica e não político-pedagógica; segundo implica em avalizar a proposta do governo no sentido de que é a flexibilidade do currículo, garantida pela parte diversificada permitiria a formação ampla para a cidadania e para o mundo do trabalho.

Apesar das divergências prevaleceu a tentativa de estabelecer uma total correspondência entre as exigências das atividades produtivas e a realização pessoal. Assim, no texto das DCNEM ao mesmo tempo em que destaca o papel relevante do ensino médio na sociedade tecnológica reduzindo o individuo a um mero fator de produção, coloca a educação como elemento definidor de quantos e quais serão os segmentos inseridos nessa sociedade tecnológica.

A esse respeito, assim se expressa o texto das DCNEM:

Em contrapartida, é importante compreender que a aproximação entre as competências desejáveis em cada uma das dimensões sociais não garante uma homogeneização das oportunidades sociais. Há que considerar a redução dos espaços para os que vão trabalhar em atividades simbólicas, em que o conhecimento é o instrumento principal, os que vão continuar atuando em atividades tradicionais e, o mais grave, os que se vêem excluídos (BRASIL/MEC, 1999, p.19).

Aqui está claramente exposto o caráter dual e excludente da educação e, a nosso ver, muitos dos que serão excluídos do mercado de trabalho formal, ou que ficarão à mercê de atividades precarizadas, são os que não conseguirão concluir o ensino médio e os que ao concluírem não puderem fazer um curso técnico, uma vez que apesar da preparação básica para o trabalho postulada pelas DCNEM enfatizar o desenvolvimento da capacidade de abstração, do pensamento sistêmico, da criatividade, da capacidade de pensar múltiplas alternativas para a solução de um problema e da capacidade de trabalhar em equipe, só esses elementos não bastam para o mercado de trabalho.

Estudos desenvolvidos por OLIVEIRA evidenciaram a preferência clara dos empresários por ex-alunos do SENAI, indicando que "existem componentes positivos, mesmo no "antiquado" e "execrado" ensino técnico-profisionalizante"(2000, p. 485).

Registramos ainda que em dois concursos realizados no Estado do Maranhão um para o Tribunal de Justiça e outro para o Tribunal Regional do Trabalho, as vagas oferecidas para 
o nível médio exigiam cursos técnicos tais como: enfermagem, mecânica de veículos, contabilidade, edificações, informática e laboratório.

Segundo KUENZER (2000), ao outorgar ao ensino médio a função de desenvolver a pessoa humana mediante a preparação de competências básicas para o trabalho e o exercício da cidadania e conferir ao ensino técnico a vertente profissionalizante, a política educacional expressa apenas uma solução ideológica, pois desconsidera as particularidades do modelo econômico brasileiro, com sua carga de desigualdades decorrentes das diferenças de classes e de especificidades resultantes de um modelo de desenvolvimento dependente, que reproduz internamente as mesmas desigualdades e os mesmos desequilíbrios e as mesmas relações que ocorre entre os países no âmbito da internacionalização do capital.

Como a produção e a reprodução da ideologia são frutos do mesmo processo que reproduz a riqueza social como capital e o trabalho como trabalho assalariado, os idealizadores das reformas procuram encobrir a exploração, quando não levam em conta a diversidade real, às diferenças entre os países ricos e pobres e as especificidades de cada região e Estado. Utilizam conceitos, concepções e expressões frutos de ideologias produzidas pelo capitalismo e procuram apresenta-los como normais e destituídos de conflitos e contradições.

A empregabilidade é um desses conceitos que cumpre uma função ideológica muito importante na sociedade capitalista contemporânea. Os trabalhadores precarizadossubcontratados, temporários, conta própria- são levados a incorporar a flexibilidade e a rotatividade como instrumentos de manutenção de sua empregabilidade. Os desempregados além de assumirem a culpa pela situação de ser sem-emprego, são encorajados a usar a criatividade para inventar o próprio trabalho.

Portanto, o novo ensino médio público proposto pela reforma não é para a vida, mas para o trabalho precarizado, para o desemprego e para a formação de clientes para os cursos técnicos particulares e aligeirados de nível médio e cursos superiores particulares. Com base exposto, destacamos que ao questionarmos a ênfase dada à questão da formação de competências básicas para o trabalho, tal como proposto pela LDB e pelas diretrizes curriculares, não estamos negando a importância da educação básica, pois a escola constitui-se numa exigência para a qualificação da força de trabalho e para as outras dimensões do processo social, Estamos criticando é a preparação para as diversas formas de trabalho precário e para o trabalho abstrato como objetivação de valores de troca e não o trabalho como "condição natural da existência humana, uma condição do metabolismo entre o homem e a natureza independentemente de qualquer forma social" (MARX, 1993, p. 42).

Chamamos atenção é para o fato de que a ênfase na educação geral deve ser vista com ponderação, para que o ensino técnico não seja suprimido da educação pública e o setor privado acabe assimilando essa modalidade como possibilidade de lucro.

Criticamos também é a tentativa do processo de esvaziamento do individuo, ou seja, a 
redução do individuo a um mero possuidor de força de trabalho em geral que pode ser trocada no mercado, pois na ótica do capital a qualificação é a capacidade de trabalho produzida socialmente, transformando homens e mulheres em força de trabalho enquanto mercadoria. A competência, por sua vez representa a possibilidade multivariada do capital usar essa capacidade de trabalho da forma que melhor lhe convier.

Apesar da relação abstrata e universal cuja expressão materializa-se no valor de troca e da defesa de uma concepção educacional voltada para a formação de indivíduos dispostos a se adaptarem à sociedade regida pela lógica do capital, concebemos formação humana como um processo de conhecimento e de realização individual que se expressa socialmente e que transpões a dimensão do agir unicamente determinado pela necessidade de subsistência, pressupondo, portanto, o desenvolvimento do individuo como particularidade e como generalidade.

Assim, compreendendo a qualificação como relação social, consideramos que esse conceito ainda é atual, uma vez que expressa as contradições das relações sociais de produção. Ademais, a noção de competência está ancorada numa dimensão individual, que subestima a dimensão social das relações sociais de trabalho. E, o trabalho na dimensão ontológica não se restringe somente ao individuo, mas está envolto no movimento contraditório de produção e reprodução da existência humana.

Nessa perspectiva, a qualificação implica fundamentalmente no controle do processo produtivo e na capacidade de realização desse processo independentemente do aparelho técnico do capital. Esta é a qualificação real, síntese de uma nova forma de sociabilidade. Por essa razão o debate teórico e ideológico sobre o papel do ensino médio e sua vinculação com o processo de formação dos trabalhadores, devem expressar essa contradição, ou seja, os movimentos, as criticas e as mais variadas formas de resistências daqueles que não se identificam com as propostas voltadas para a adaptação das pessoas aos modelos estabelecidos pelos detentores do capital.

$\left(^{*}\right)$ Maria José Pires Barros Cardozo, doutoranda em Educação Brasileira pela Universidade Federal do Ceará, professora assistente do curso de Pedagogia da Universidade Federal do Maranhão isoamri@bol.com.br

\section{REFERÊNCIAS BIBLIOGRÁFICA}

ANTUNES, Ricardo. Adeus ao trabalho: ensaio sobre a metamorfose e a centralidade no mundo do trabalho. 3 ed. São Paulo: Cortez, 1995.

Os sentidos do trabalho: ensaio sobre a afirmação e a negação do trabalho. São Paulo: Boitempo Editorial,1999.

BLOOM, Bejamim S. Et.all. Taxinomia de objetivos educacionais: o domínio cognitivo. Porto Alegre: Globo, 1973.

BRASIL. Ministério da Educação. Parâmetros curriculares nacionais: ensino médio. Brasília: MEC/SEMTC, 1999.

Eixos cognitivos do enem. Brasília: MEC/INEP, 2002.

Competências, conhecimentos e valores na concepção curricular do novo 
ensino médio. Brasília: MEC, 2004, disponível em http//www.mec.gov.br.ensmed.artigo.doc.

educação básica. Brasília: MEC/INEP, 2000.

Matrizes curriculares de referencia para o sistema de avaliação da Ministério da Ciência e Tecnologia. Educação para a competitividade. Brasília: MCT/FINEP, v. 1, 1995.

BRAVERMAN, H.. Trabalho e capital monopolista. Rio de Janeiro: Zahar, 1991.

BRUNO, Lúcia. Educação, qualificação e desenvolvimento econômico. In: Educação e trabalho no capitalismo contemporâneo: leituras selecionadas. São Paulo: Atlas, 1996.

CHESNAIS, François. A mundialização do capital. São Paulo: Xamã,1995.

CORAGGIO, J. L. Proposta do banco mundial para a educação: sentido oculto ou problemas de concepção?. In: Tomasi, L.; Warde, M., Haddad, S. (orgs.). O Banco mundial e as políticas educacionais. São Paulo: Cortez, 1996.

DUARTE, Newton. Vigotski e o "aprender a aprender": crítica às apropriações neoliberais e pós-modernas da teoria vigotskitiana. 2 ed. Campinas: Autores Associados, 2001.

DUBAR, Claude. A sociologia do trabalho frente à qualificação e à competência. In: Educação \& Sociedade, Campinas. Ano 19 n. 64 p. 87-103, 1998.

GRAMSCI. A. Os intelectuais e a organização da cultura. Rio de Janeiro: Civilização Brasileira, 1968.

HIRATA, Helena. $O(s)$ mundo(s) do trabalho: convergência e diversidade num contexto de mudanças dos paradigmas produtivos. São Paulo, 1996(mimeo).

KUENZER, Acácia Zeneida. O ensino médio agora é para a vida. In: Educação \& Sociedade, Campinas, ano 21 n. 70 p. 15-39, 2000.

. Exclusão includente e inclusão excludente: a nova forma de dualidade estrutural que objetiva as novas relações entre educação e trabalho. In: Capitalismo, trabalho e educação (org.) LOMBARDI, J. C. (et all). Campinas: Autores Associados. 2002, p. 77-96.

LEITE, Márcia de Paula. O futuro do trabalho: novas tecnologias e subjetividade operária. São Paulo: Scritta, 1994.

A qualificação reestruturada e os desafios da formação profissional. Novos Estudos. São Paulo, jul.,1996.

MACHADO, Lucília R. S. Mudanças tecnológicas e a educação da classe trabalhadora. In: Trabalho e educação. 2. ed. São Paulo: Papirus,1994.

Qualificação do trabalho e relações sociais. In: FIDALGO, Fernando S.

(org). Gestão do Trabalho e formação do trabalhador. Belo Horizonte: MCM, 1996.

MAIA FILHO, Osterne N.. A reforma do ensino médio: da pegagogia das competências à gestão tecnocrata em educação. Tese de doutorado.Universidade Federaldo Ceará, Fortaleza, 2004.

MARANHÂO, Gerencia de Desenvolvimento Humano. Referenciais curriculares do ensino médio do Estado do Maranhão. São Luís:GDH, 2003.

MARX, Karl, O capital. Rio de Janeiro: Bertrand Brasil, 1989.

Salário, preço e lucro. In: Para a critica da economia política. São Paulo:

Abril cultural, 1982. (Os economistas).

O capital. V 1, L 1 .Tomo 1. São Paulo: Abril Cultural, 1983. (Os

economistas) 
economistas)

.O capital. V. 1, L 1, Tomo 2. São Paulo: Abril Cultural, 1984. (Os

Manuscritos econômico-filosóficos. Lisboa. Edições 70, 1993.

. Los fundamentos de la critica de la economia política. V 1. Madrid: Editora Alberto/Corazon, 1972.

OLIVEIRA, João Batista. Quem ganha e quem perde com a política do ensino médio no Brasil. In: Ensaio.v 8 n. 29. Rio de Janeiro: Fundação Cesgranrio, 2000. p. 405-576

PIAJET, J. A equilibração das estruturas cognitivas. Rio de Janeiro: Zahar, 1976.

RAMOS, Marise Nogueira. A pedagogia das competências: autonomia ou adaptação? São Paulo: Cortez, 2001.

TANGY, Lucie. La formattion, une activité sociale en voie de definition. In: COSTA, Michel, PICHANT, Francois. Tratié de sociologie du travail. Bruxellas: Ed. Boecla Université, 1994.

Paulo: Papirus, 1997. Saberes e competências: o uso de tais noções na escola e na empresa. São

\section{volta}

